\title{
Corneal sensitivity and ocular surface changes following preserved amniotic membrane transplantation for nonhealing corneal ulcers
}

Eye (2003) 17, 139-148. doi:10.1038/

sj.eye. 6700346

\section{Introduction}

Compromised ocular surface defence caused by malfunction of lids or tear film, nerve damage, corneal infection and chronic inflammation may lead to persistent epithelial defects and corneal stromal melting. Persistent corneal epithelial defects caused by primary or secondary ocular surface disorders may be difficult to treat and usually induce prolonged inflammation of the ocular surface, loss of corneal stem cells, and destruction of the epithelial basement membrane, resulting in corneal scarring, neovascularisation, and decreased vision. ${ }^{1,2}$ Conservative treatment of epithelial defects with stromal ulceration consists of treatment modalities such as continous pressure patching or therapeutic soft contact lenses with preservative-free lubricants and punctum occlusion. ${ }^{3}$ Patients failing to respond to a medical approach may eventually require a surgical procedure like tarsorraphy or penetrating keratoplasty. ${ }^{4,5}$ Lee and Tseng ${ }^{6}$ initially proposed the use of human amniotic membrane for the treatment of epithelial defects with stromal ulcers that remain recalcitrant to conventional treatments. Subsequently, successful applications of amniotic membrane transplantation (AMT) in cicatricial eye diseases, pterygium surgery and ocular surface reconstruction were described. ${ }^{7-9}$ Amniotic membrane consists of a thick basement membrane and an avascular stroma that contains a high concentration of basic fibroblast growth factor, basement membrane components, and presumed trophic factors. The
M Dogru, M Yildiz, M Baykara, H Özçetin and H Ertürk

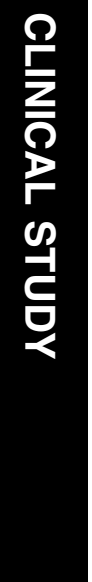

stromal matrix of the amniotic membrane is known to have the ability to exclude the inflammatory cells and promote healing. ${ }^{6}$ The aim of this study was to investigate the effect of preserved human amniotic membrane in the treatment of nonhealing corneal ulcers and also investigate the timewise effects on corneal sensitivity, tear function, and impression cytology parameters.

\section{Materials and methods}

A total of 10 eyes of 10 patients (seven males; three females) aged between 25 and 76 years (mean: $54.5 \pm 16.5$ years) underwent preserved amniotic membrane transplantation between April 2000 and April 2001 for persistant corneal epithelial defects with stromal ulceration. All patients were initially treated with removal of toxic topical antibiotics, lubrication, autologous serum eye drops and with a bandage contact lens/pressure patching for at least 8 weeks. A total of 44 patients diagnosed with corneal ulcers owing to infectious keratitis, alkali injury, diabetic neuropathy, or dry eyes responded to the above-mentioned conventional approach during the same period. Tarsorraphy was suggested when these techniques were unsuccessful. The 10 patients in this series did not opt for a tarsorraphy procedure. None of the patients had a history of atopy, Stevens-Johnson syndrome, thermal or radiation injury, or contact lens use for refractive purposes before amniotic membrane transplantation. Three patients had type II diabetes mellitus, which was not under good control (a fasting blood glucose level of greater than $140 \mathrm{mg} / \mathrm{dl}$ and a glycosylated haemoglobin level of greater than 7.8\%) throughout this study. Patients with herpe simplex keratitis received oral acyclovir
Department of Ophthalmology Faculty of Medicine Uludag University Bursa, Turkey

Correspondence: M Dogru Department of Ophthalmology Tokyo Dental College Ichikawa General Hospital Sugano 5-11-13, Ichikawa Chiba 272-8513, Japan Tel: + 81473220151 Fax: + 87473226786 E-mail: muratodooru@ yahoo.com

Received: 20 November 2001

Accepted in revised form: 19 June 2002 
$1000 \mathrm{mg} /$ day as well as $60 \mathrm{mg}$ /day of prednisolone for 1 week, followed by gradual tapering of oral corticosteroids. Patients with postinfectious keratitis received sufficient systemic and topical antibiotics/ antifungals to eradicate the causative organisms. None of these patients had clinical or microbiologic signs of acute corneal infection at the time of amniotic membrane transplantation. The 10 patients in whom the corneal epithelial defects did not close despite all mentioned attempts received amniotic membrane transplantation. Two patients had herpetic and three others had postinfectious corneal ulcers. The ulcers were because of alkali burn in two eyes and were of neurotrophic nature in two eyes. One other eye had a persistant epithelial defect on the corneal graft after penetrating keratoplasty. Clinical features of the patients are summarised in Tables 1 and 2. Routine ophthalmic examinations consisted of best-corrected visual acuity (BCVA) measurements, anterior segment photography, and slit-lamp examination. Corneal thickness was evaluated using biomicroscopy or ultrasonic pachymetry (Biomed, France) before and after the operation at each visit. Stromal thickness was recorded and compared with the thickness of the same area after the operation only when the surgical area was completely epithelialised. A stromal ulcer with keratolysis exceeding $50 \%$ of corneal stromal thickness was regarded as a deep ulcer in this study. Increase in stromal thickness of the eyes at the last follow-up as observed by careful biomicroscopy and anterior segment photography was defined as 'stromal gain'. The patients underwent ocular surface examinations including corneal sensitivity measurements, tear film break-up time (BUT), Schirmer test, and conjunctival impression cytology. The patients were required not to have instilled their medications at least $6 \mathrm{~h}$ prior to these examinations. All examinations were performed by the same researcher. An informed consent about the procedures was obtained. Tear function and corneal sensitivity measurements were performed before amniotic membrane transplantation, with epithelisation, attainment of resolution of the membrane, and at the last follow-up. Corneal sensitivity was measured using a Cochet-Bonnet aesthesiometer. The measurements were begun with the nylon filament fully extended. The tip of the nylon filament was applied perpendicular to the surface of the corneal lesion making certain not to touch the eyelashes and was pushed until the fibre's first visible bending. The length of the fibre was gradually decreased until a blink reflex was observed. The length was recorded in units of millimetre. A corneal sensitivity measurement of less than $50 \mathrm{~mm}$ was regarded as low corneal sensitivity in this study.

The standard tear film BUT measurement was performed. Moistened fluorescein strips were introduced into the conjunctival sac with minimal stimulation and were undetected by the patients. The subjects were then instructed to blink several times for a few seconds to ensure adequate mixing of fluorescein. The interval between the last complete blink and the appearance of the first corneal black spot in the stained tear film was measured three times and the mean value of the measurements was calculated. A BUT value of less than $10 \mathrm{~s}$ was considered abnormal.

For further evaluation of tears, the standard Schirmer test with topical anaesthesia ( $0.4 \%$ oxybuprocaine chloride) was performed. The standardised strips of filter paper (Alcon, TX, USA) were placed in the lateral canthus away from the cornea and left in place for $5 \mathrm{~min}$ with the eyes closed. Readings were reported in millimetres of wetting for $5 \mathrm{~min}$. A reading of less than $5 \mathrm{~mm}$ was referred to as dry eye.

The impression cytology specimens were obtained after administration of topical anaesthesia with $0.4 \%$

Table 1 Clinical features of the patients

\begin{tabular}{|c|c|c|c|c|c|c|c|}
\hline Case & $\begin{array}{l}\text { Age (year)/ } \\
\text { sex }\end{array}$ & $\begin{array}{c}\text { Cause of } \\
\text { ulcer }\end{array}$ & $\begin{array}{l}\text { Size of } \\
\text { ulcer } \\
(\mathrm{mm})\end{array}$ & $\begin{array}{l}\text { Duration } \\
\text { of ulcer } \\
\text { (months) }\end{array}$ & $\begin{array}{c}\text { Associated ocular } \\
\text { surface and other } \\
\text { problems }\end{array}$ & Prior treatment/surgery & $\begin{array}{l}\text { Total limbal } \\
\text { dysfunction }\end{array}$ \\
\hline 1 & $46 / \mathrm{M}$ & HSV & $4 \times 4$ & 2.5 & $\% 90$ thinning & PP, AS, lubricants & No \\
\hline 2 & $50 / \mathrm{M}$ & HSV & $3 \times 4$ & 4.0 & $\% 90$ thinning & PP, AS, lubricants & No \\
\hline 3 & $75 / \mathrm{M}$ & Neurotrophic & $6 \times 3$ & 2.5 & $\% 75$ thinning, KCS & $\begin{array}{l}\text { TCL, AS, lubricants, } \\
\text { PO, ECCE }\end{array}$ & No \\
\hline 5 & $43 / F$ & Postinfectious & $5 \times 5$ & 4.0 & $\% 50$ thinning & SK, TCL, lubricants & No \\
\hline 6 & $47 / \mathrm{M}$ & Postinfectious & $6 \times 7$ & 3.0 & $\% 90$ thinning & TCL, SK, lubricants & No \\
\hline 7 & $73 / \mathrm{M}$ & Postinfectious & $7 \times 7$ & 2.5 & $\begin{array}{l}\% 75 \text { thinning, KCS, } \\
\text { glaucoma, DM }\end{array}$ & TCL, SK, lubricants & No \\
\hline 8 & $26 / \mathrm{M}$ & Alkali burn & $5 \times 4$ & 3.0 & $\begin{array}{l}\% 90 \text { thinning, entropion, } \\
\text { trichiasis, KCS, CM }\end{array}$ & $\begin{array}{l}\text { LT, SC, SK, lubricants, } \\
\text { TCL, LFR, LME }\end{array}$ & Yes \\
\hline 9 & $45 / \mathrm{F}$ & Alkali burn & $4 \times 4$ & 4.0 & $\% 40$ thinning, KCS, CM & TCL, SK, lubricants & Yes \\
\hline
\end{tabular}


Table 2 Amniotic membrane transplantation (AMT) results

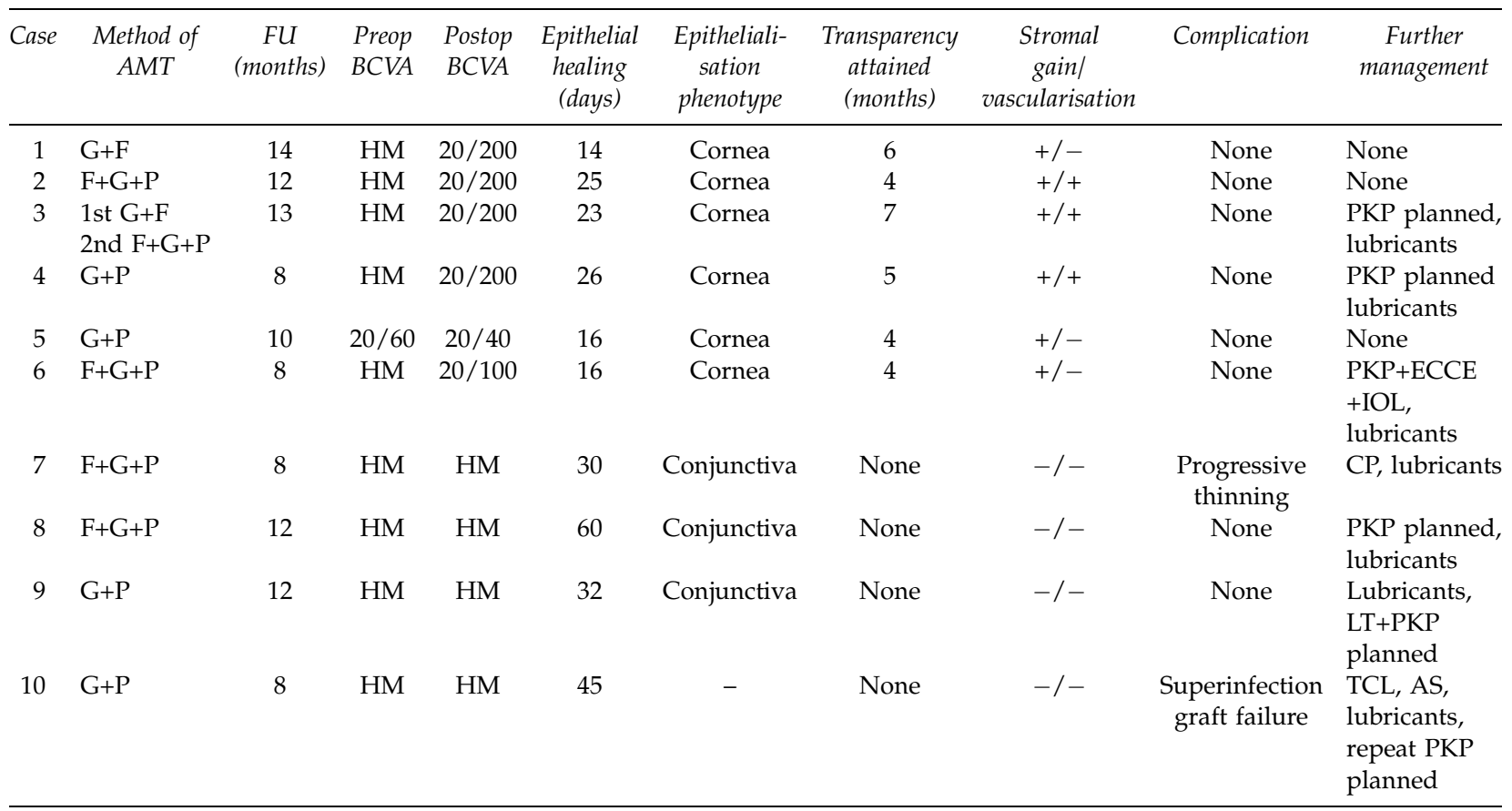

Note: G+F: graft+filling; G+P: graft+patch; F+G+P: filling+graft+patch; HM: hand motion; PKP: penetrating keratoplasty; ECCE: extracapsular cataract extraction; IOL: intraocular lens; CP: conjunctival patching; LT: limbal transplant; TCL: therapeutic contact lens; AS: autologous serum; FU: follow-up; BCVA: best-corrected visual acuity.

oxybuprocaine chloride. Impression cytology was carried out at the initial and the final follow-up visits. Strips of cellulose acetate filter paper (Millipore HAWP 304, Bedford, MA, USA) that were soaked in distilled water for a few hours and dried at room temperature were applied on the lower nasal bulbar conjunctiva adjacent to the corneal limbus, pressed gently by a glass rod, and then removed. The specimens were then fixed with formaldehyde, stained with periodic acid schiff (PAS), dehydrated in ascending grades of ethanol and then with xylol, and finally coverslipped. The quantitative studies of conjunctival goblet cells and squamous metaplasia of conjunctival epithelial cells were conducted by taking photographs using a calibrated grid under a light microscope at a magnification of $\times 400$. We photographed five overlapping areas of each sample selected at random and averaged the outcomes for a single sample score. The goblet cell densities were reported as cells per square millimetre with standard deviations. The specimens were also assigned a grade of conjunctival epithelial squamous metaplasia according to the grading scheme of Nelson. ${ }^{10}$

\section{Preparation of preserved human amniotic membrane}

Human placentas were obtained under sterile conditions from planned, uneventful caesarean sections performed because of anatomic considerations. A written consent was obtained from the mothers to harvest the amniotic membrane. Maternal blood was screened for antibodies against syphilis, human immunodefficiency virus, and hepatitis virus types B and C. The placentas were washed free of blot clots with balanced saline solution containing $50 \mu \mathrm{g} / \mathrm{ml}$ of penicillin, $50 \mu \mathrm{g} / \mathrm{ml}$ of streptomycin, $100 \mu \mathrm{g} / \mathrm{ml}$ of neomycin, and $2.5 \mu \mathrm{g} / \mathrm{ml}$ of amphotericin B. The amniotic membrane was separated from the rest of the chorion by blunt dissection. The membranes were then flattened and sutured with the epithelium surface up onto nitrocellulose filter papers. The membrane with the paper was then placed in sterile vials containing Optisol-GS (Bausch \& Lomb, CA, USA) and glycerol at a ratio of $1: 1$ (volume/volume). The vials were then frozen and stored at $-80^{\circ} \mathrm{C}$. The membranes were not released for use after a second serologic testing for HIV and hepatitis viruses from the donor, performed 6 months after donation, proved negative. The membranes were defrosted by warming the vials to room temperature for $10 \mathrm{~min}$ immediately before use.

\section{Amniotic membrane transplantation}

Surgery was performed under retrobulbar anaesthesia. The base of the ulcer was debrided with a microsponge 
and fine forceps, and the poorly adherant epithelium adjacent to the edge of the ulcer was removed up to the area where the epithelium became adherant. The amniotic membrane was then removed from the storage medium, peeled from the nitrocellulose filter paper, transferred to the recipient eye, and fitted to fill up the ulcer bed and cover the defect by trimming off the excess edges. This stroma-side down was then secured to the edges of the ulcer by interrupted 10/0 nylon sutures and the suture knots were buried. The decision for transplanting more than one layer of amniotic membrane was made by a careful assessment of preoperative and intraoperative ulcer depth with the aid of slit-lamp biomicroscopy and surgical microscope. More than one layer of amniotic membrane was used if the ulcer was deep, and in those instances, the bottom layers were left unsutured as a filling. The second amniotic membrane layer was transplanted as a basement membrane (amniotic membrane graft). Depending on the aqueous tear status and the eyelid blinking function, a third amniotic membrane layer was transplanted as a cover (amniotic membrane patch). When amniotic membrane was used as a patch, this was performed by placing the amniotic membrane over the cornea and extending it beyond the limbus with the basement membrane side facing down and suturing it with 10/0 interrupted nylon sutures over the perilimbal area.

\section{Postoperative care}

Before epithelialisation, the patients were followed weekly and were treated with topical $0.1 \%$ prednisolone acetate (patient 10) three times a day or nonpreservative $0.4 \%$ dexamethasone three times a day (patients 1-9) and topical $0.3 \%$ ofloxacin eye drops twice a day. After epithelialisation was completed, the antibiotic eye drops were discontinued but the former was gradually tapered off over 4 months. Patients with dry eye received topical preservative-free artificial tears or autologous serum drops six to eight times a day as well.

\section{Statistical analysis}

Data were processed using Stat View software (1988, Abacus Concepts, Inc., San Diego, CA, USA). The analysis of categorised data was performed by Fisher's exact probability test with the probability level set at $5 \%$ for statistical significance.

\section{Results}

\section{Before AMT}

Seven eyes in this series had received previous ocular surgery before amniotic membrane transplantation. One eye had received repeat keratoplasty owing to graft failure. Corneal stroma showed variable amounts of opacity before amniotic membrane transplantation in all eyes. In addition, other preexisting ocular diseases such as glaucoma and diabetic retinopathy had threatened the visual potential in our patients. Owing to these problems, all eyes except one had a visual acuity equal to hand motions before amniotic membrane transplantation.

According to the respective histories, all the ulcers had been persistent for more than 2 months, showing progressive thinning of the ulcer bed. All corneas had significant corneal oedema, inflammation of the limbus and the conjunctiva.

\section{After AMT}

Depending on the depth of stromal ulceration, the ulcers were covered by one or more than one layer of amniotic membrane. Amniotic membrane transplantation had to be performed twice in one patient (case 3) because of membrane disinsertion from eye rubbing. The denuded ulcer surfaces healed uneventfully with amniotic membrane transplantation in all patients except case 10 between 14 and 60 days (mean: $28.7 \pm 14.3$ days). Amniotic membrane transplantation could suppress the ocular surface inflammation as evidenced by the decrease of conjunctival and limbal hyperaemia and corneal oedema. The ulcers healed with corneal epithelial phenotype in six eyes in which total or partial stromal gain could be achieved. A decrease of stromal vascularisation was noted in three eyes (Table 2). In case 7 , the corneal surface showed further thinning with signs of imminent perforation, which led us to perform conjunctival patching. A corneal epithelial phenotype could not be attained in cases 8 and 9 who had total limbal dysfunction, keratoconjunctivitis sicca, and chronic meibomitis. The amniotic membrane was removed in case 10 upon detection of profuse secretion on postoperative day 6 when the membrane remnants and the therapeutic contact lens proved positive for Staphylococcus aereus infection. This patient was treated with fortified vancomycin and oflaxocin eye drops effectively and was put on list for repeat penetrating keratoplasty upon refusal to undergo a second AMT. During the mean follow-up period of $10.5 \pm 2.4$ months, visual acuity improved in the six eyes with corneal epithelial phenotype (Table 2). Five patients lost their therapeutic contact lenses twice until epithelialisation. All the membranes were completely or partially dissolved, and the remaining stroma showed variable amounts of opacity. Figures 1-4 show the slit and anterior segment photographs of case 2 with herpetic ulcer before and after amniotic membrane transplantation and at the final visit. Figures 5-7 


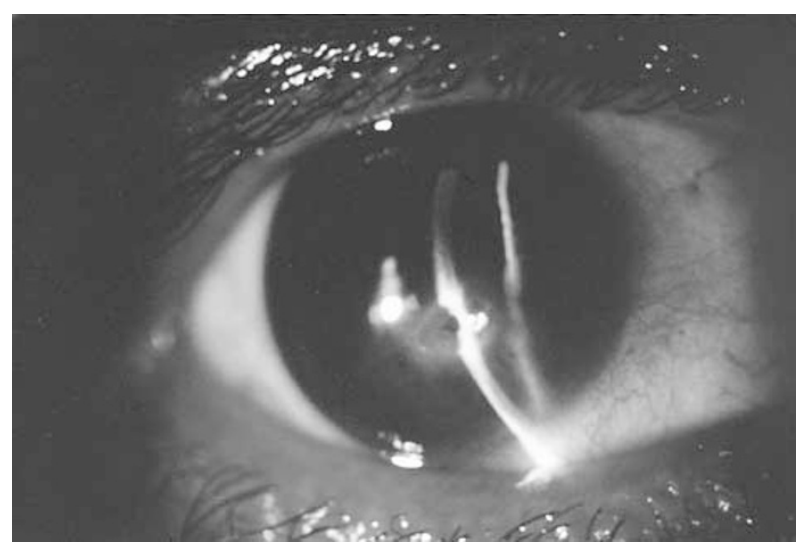

Figure 1 Slit-lamp photography of a case with herpetic ulcer before AMT. Corneal sensitivity: $32.5 \mathrm{~mm}$, BUT: $3 \mathrm{~s}$, Schirmer test: $8 \mathrm{~mm}$.

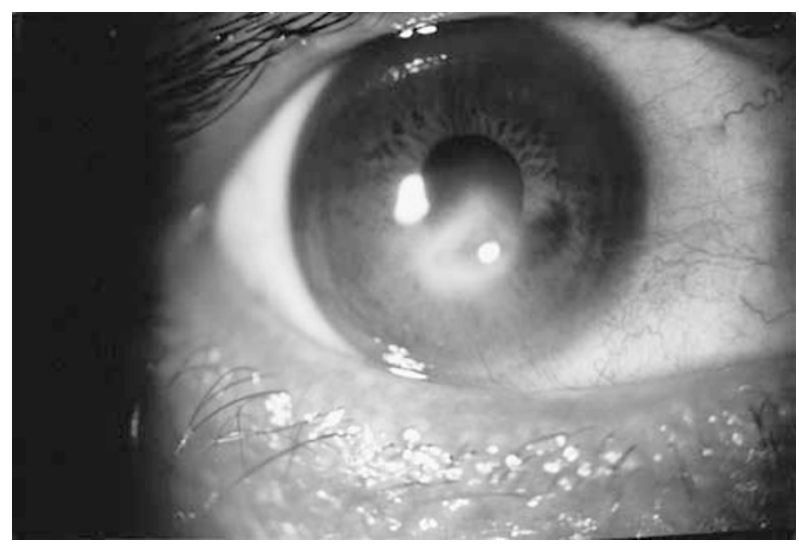

Figure 2 Anterior segment photography of the same case before AMT.

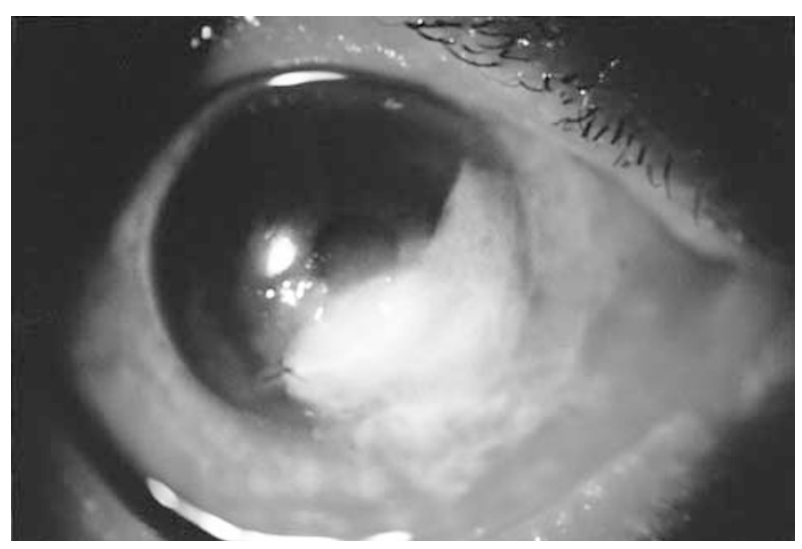

Figure 3 Anterior segment photography after AMT performed as filling + graft.

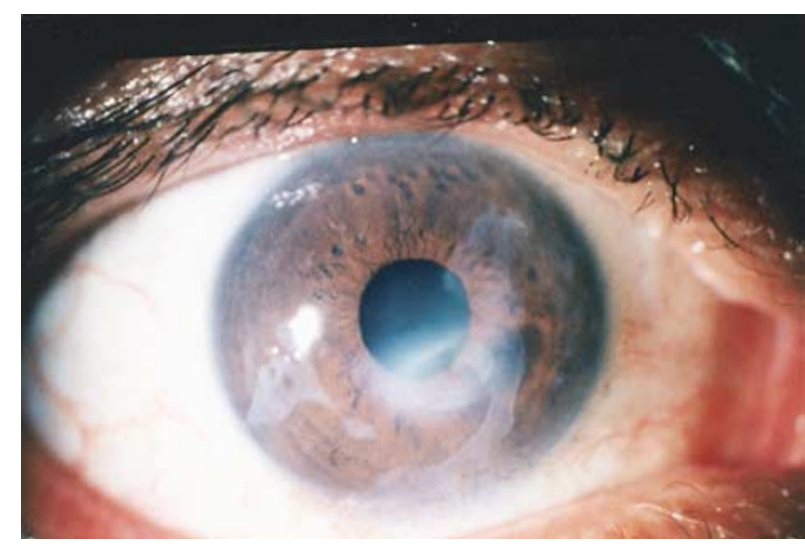

Figure 4 Anterior segment photography at the 12th postoperative month. Note the stromal gain and attainment of corneal transparency. Corneal sensitivity: $47.5 \mathrm{~mm}$, BUT: $9 \mathrm{~s}$, Schirmer test: $8 \mathrm{~mm}$.

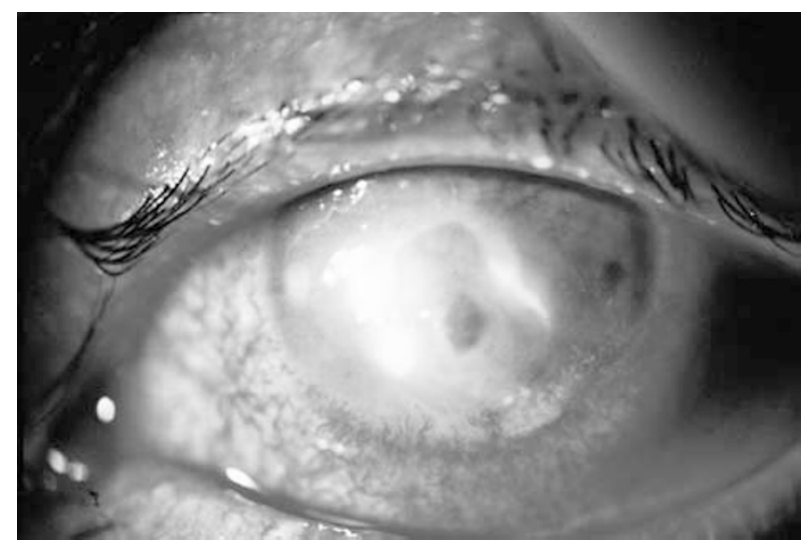

Figure 5 Anterior segment photography of a case with neurotrophic ulcer before AMT. Corneal sensitivity: $20 \mathrm{~mm}$; BUT: $1 \mathrm{~s}$, Schirmer test: $3 \mathrm{~mm}$.

represent the anterior segment photographs of case 3 with neurotrophic ulcer before and after the first and the second transplantation.

\section{Corneal sensitivity}

The corneal sensitivity improved in all patients except case 10 after amniotic membrane transplantation. The mean pretransplantation corneal sensitivity was $29.5 \pm 4.25 \mathrm{~mm}$, which improved to a mean value of $41.75 \pm 3.85 \mathrm{~mm}$ at the final follow-up. The mean corneal sensitivities at the time of attainment of amniotic membrane resolution and at the final visit were significantly higher than the preoperative values $(P<0.05)$. The change of corneal sensitivity with amniotic membrane transplantation is 


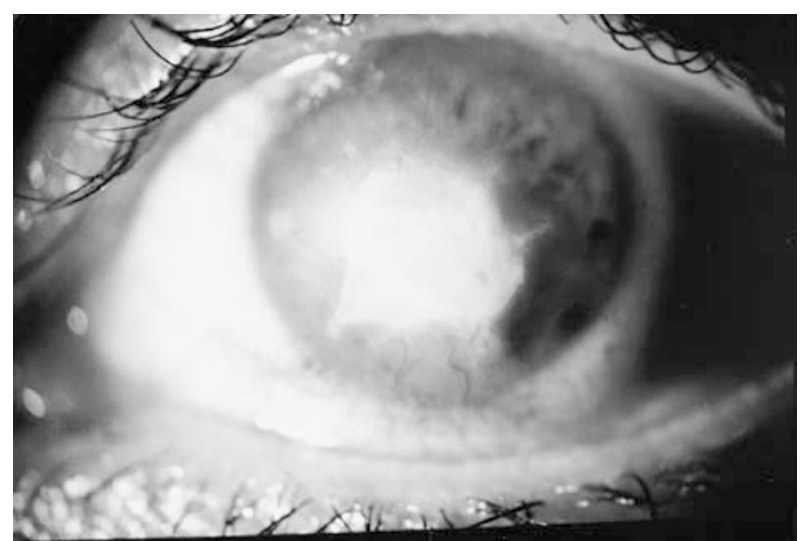

Figure 6 Anterior segment photography after the first AMT performed as filling + graft. Note the decrease of limbal and conjunctival hyperaemia and corneal oedema.

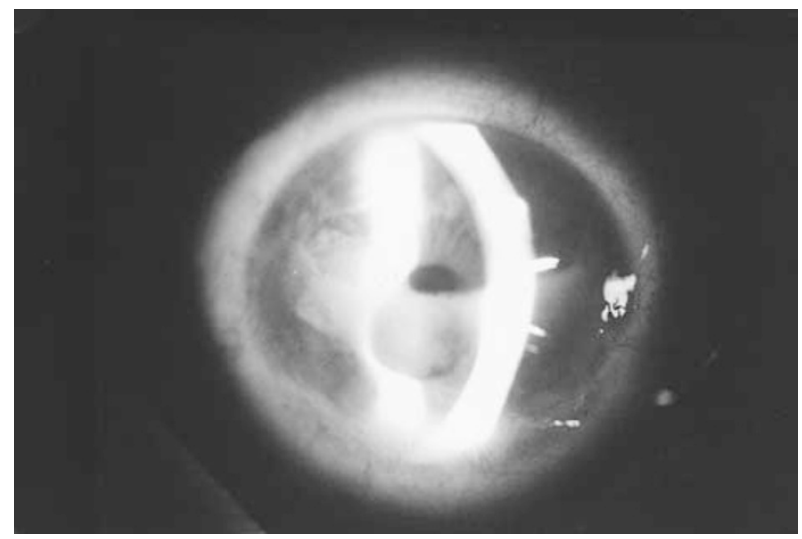

Figure 7 Anterior segment photography after second AMT performed as filling + graft + patch. Note the regression of superior and inferior corneal stromal vascularisation and stromal gain. Corneal sensitivity: $45 \mathrm{~mm}$; BUT: $6 \mathrm{~s}$; Schirmer test: $4 \mathrm{~mm}$.

shown in Figure 8. The extent of corneal sensitivity recovery seemed to be better in patients with herpetic and neurotrophic ulcers (Figure 9).

Tear function parameters The tear film BUT improved in all patients except case 10 after amniotic membrane transplantation. The mean pretransplantation BUT increased from $1.5 \pm 0.7$ to $6.5 \pm 2.7 \mathrm{~s}$ at the final visit (Figure 10). The mean BUT values at the time of attainment of amniotic membrane resolution and at the final visit were significantly higher than the preoperative values $(P<0.05)$. Five eyes had aqueous defficiency-type dry eye in this study. Schirmer test values did not seem to differ significantly with amniotic membrane transplantation (Figure 11).

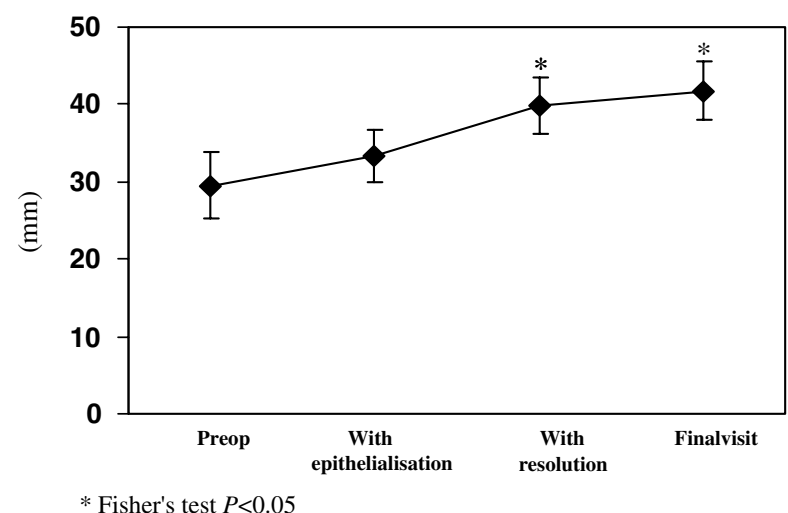

Figure 8 Change of corneal sensitivity with AMT. Note the constant increase in the mean corneal sensitivity for all patients after AMT, which showed statistical significance with resolution of the membrane and at the final visit.

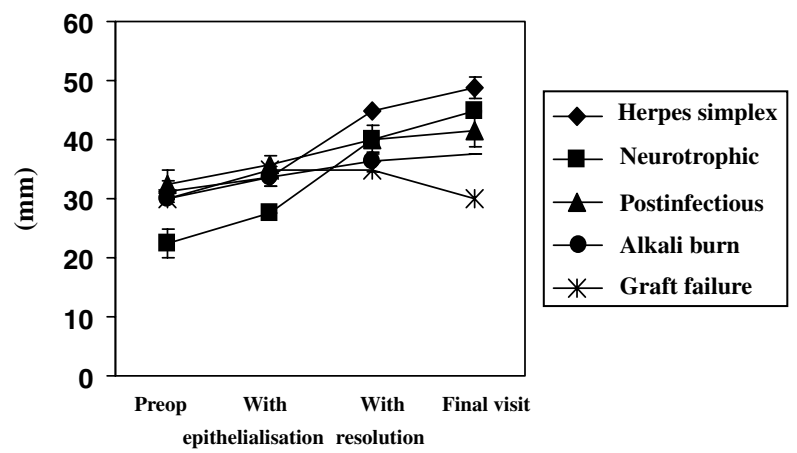

Figure 9 Aetiology-specific change of corneal sensitivity with AMT. Note the extent of corneal sensitivity recovery in patients with herpetic and neurotrophic ulcers compared to the others and the decline in the sensitivity value for the patient with graft failure at the final visit.

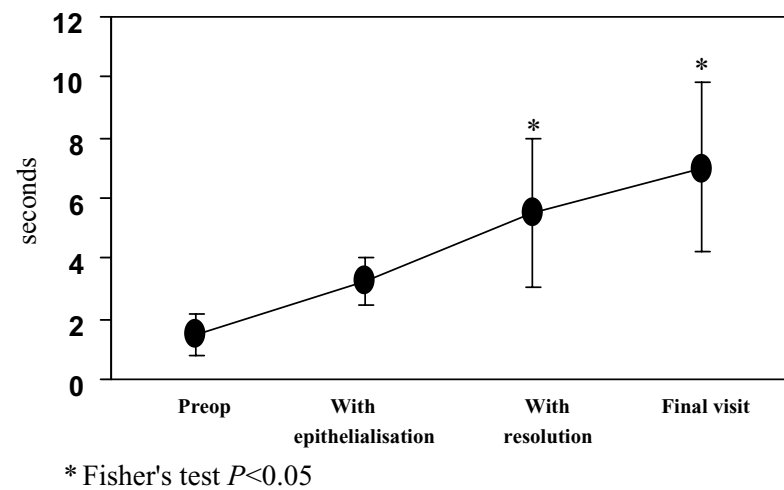

Figure 10 Change of BUT with AMT. Note the gradual improvement of the mean tear film BUT for all patients after AMT, which showed statistical significance with resolution of the membrane and at the final visit. 


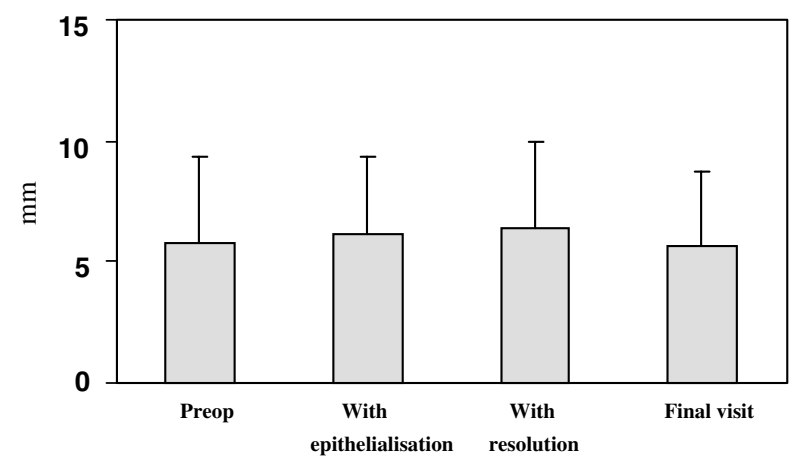

Figure 11 Change of the Schirmer test with AMT. Note that the mean Schirmer test values did not show significant differences between the follow-up visits.

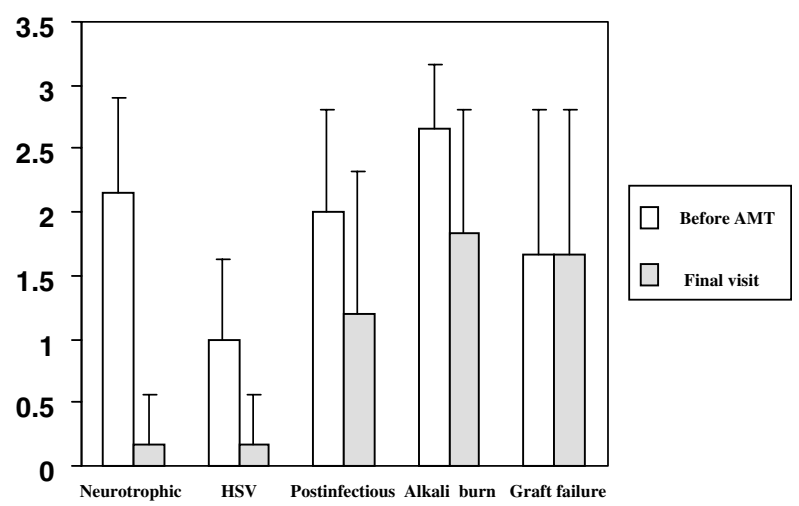

Figure 12 Aetiology-specific change of squamous metaplasia grade with AMT. Note the marked improvement in the impression cytology squamous metaplasia grade in patients with herpetic and neurotrophic ulcers with AMT compared to the others.

Impression cytology parameters Specimens showed variable degrees of goblet cell expression, conjunctival epithelial squamous metaplasia, and mucin pick-up. Except for case 10, goblet cell density and the squamous metaplasia grade were seen to have improved at the final visit. The mean preoperative and final goblet cell densities were $296 \pm 250$ and $648 \pm 445$ cells $/ \mathrm{mm}^{2}$, respectively. The mean pretransplantation squamous metaplasia grade improved from $1.92 \pm 0.88$ to $0.92 \pm 1.08$ at the final examination. These differences were significant $(P<0.05)$.

The extent of improvement in squamous metaplasia grade and goblet cell density seemed to be better in patients with herpetic and neurotrophic ulcers (Figures 12 and 13). Figures 14 and 15 show the impression cytology specimens of case 2, while Figures 16 and 17 represent the cytologic changes before amniotic membrane transplantation and at the last examination.

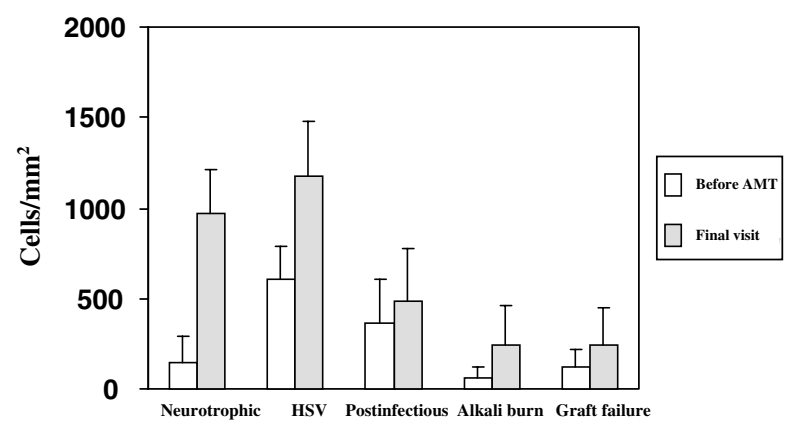

Figure 13 Aetiology-specific change of goblet cell density with AMT. Note the marked increase in goblet cell density in patients with herpetic and neurotrophic ulcers after AMT compared to the others.

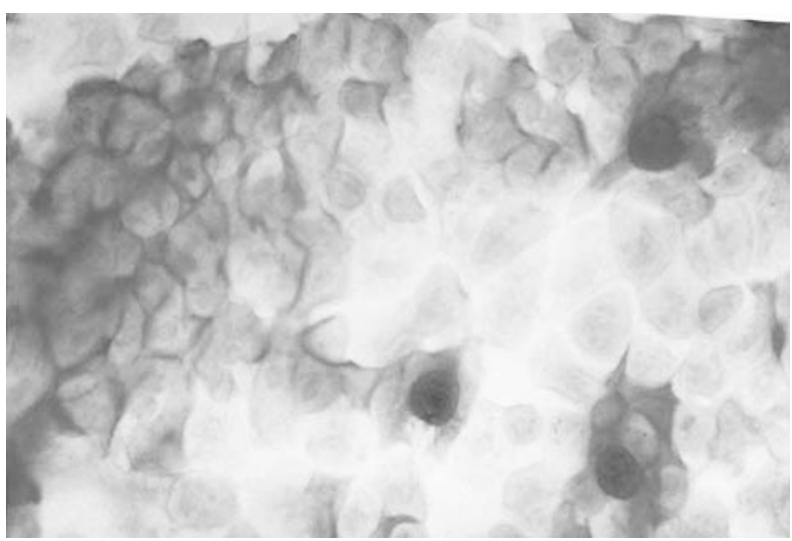

Figure 14 Impression cytology from subject with herpetic ulcer before AMT: a few PAS-positive oval-plum goblet cells and sheets of small round nonsecretory epithelial cells. SM grade: $1.33 \pm 0.57$, goblet cell density: $545 \pm 182$ cells $/ \mathrm{mm}^{2}$.

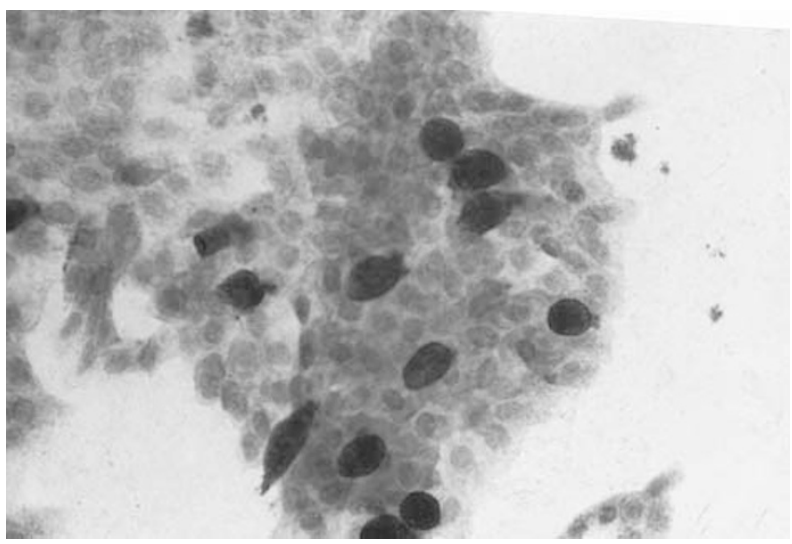

Figure 15 Impression cytology specimen of the same patient after AMT (final visit). Note the increase of goblet cells and improvement of SM grade. SM grade: $0.66 \pm 0.52$, goblet cell density: $1272 \pm 180$ cells $/ \mathrm{mm}^{2}$. 


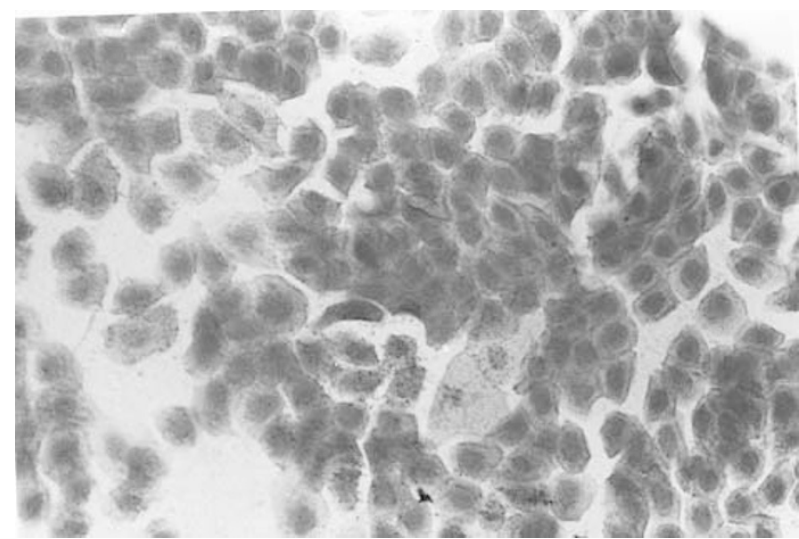

Figure 16 Impression cytology specimen from patient with neurotrophic ulcer before AMT. Note the loss of cellular cohesion, nuclear pycknosis and increased SM grade. SM grade: $2.33 \pm 0.57$, goblet cell density: $120 \pm 104$ cells $/ \mathrm{mm}^{2}$.

\section{Discussion}

Previous studies reported that the amniotic membrane has unique properties, including antibacterial, woundprotecting, epithelialisation-promoting, and fibrosissuppressing effects owing to the presence of several proteinase inhibitors, such as $\alpha_{1}$-antichymotrypsin, $\alpha_{2}$-macroglobulin, $\alpha_{1}$-antitrypsin, $\alpha_{2}$-antiplasmin, and inter- $\alpha_{1}$-trypsin inhibitor, as well as tissue inhibitors of MMP-1 and MMP-2 (which inhibit destruction of stromal collagen by MMP-2 and MMP-9), cystatin E (an analogue of cysteine proteinase inhibitor) with complementary antiviral properties, and also heat shock proteins with cytoprotective functions. In addition, amniotic membrane consists of a thick basement membrane and an avascular stroma with a high concentration of basic fibroblast growth factor, basement membrane components, and presumed trophic factors, which collectively provide benefits to augment epithelial and stromal wound healing. ${ }^{11-20}$ We expected all these unique properties of the amniotic membrane to improve the epithelialisation in our patients. In addition to taking advantage of these properties, we also took advantage of the amniotic membrane to supplement the collagen by using it as a filling in cases with deep stromal keratolysis. Moreover, we made use of the amniotic membrane as a patch in some cases to achieve constant protection and wetting of the ulcerated area to minimise surface exposure. We believed that a combination of collagen layer supplementation, augmentation of corneal surface wetting, basement membrane reconstruction, and promotion of epithelialisation and wound healing was required to treat severe nonhealing ulcers. In our experience, AMT could effectively heal the ulcers similar to other reports. ${ }^{21-26}$ The healing was with corneal

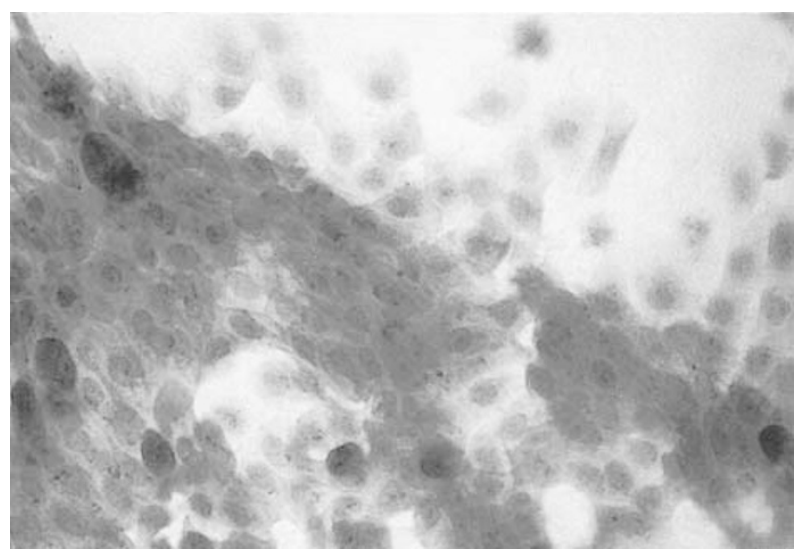

Figure 17 Impression cytology specimen from the same patient with neurotrophic ulcer after AMT (final visit). Note the increase of goblet cells and improvement of SM grade. SM grade: $0.66 \pm 1.15$, goblet cell density: $848 \pm 277$ cells $/ \mathrm{mm}^{2}$.

epithelial phenotype in six eyes. Three eyes healed by conjunctival epithelial phenotype which can be explained by the difference in the cause of the epithelial defects, associated problems and the previous treatments, and thus by the extent of initial damage to the ocular surface. Failure of attainment of corneal epithelial phenotype of healing in case 9 reconfirmed the common belief that AMT alone is insufficient in cases with total limbal dysfunction. ${ }^{27}$ The initial and consistent finding in all patients was a reduction in the ocular inflammation in the early phase after AMT as evidenced by a decrease of conjunctival and limbal hyperaemia, and corneal oedema. We observed that AMT could improve visual acuity, probably owing to both corneal surface restoration and improvement of corneal transparency. ${ }^{23}$ However, the visual results in our patients also suggest that the effect of AMT on visual rehabilitation is limited. A donor cornea may be the most suitable material for grafting to treat a nonhealing ulcer and to achieve visual rehabilitation. We think that in emergencies such as ulcers with descemetocele and impending perforation, it may be too late by the time a donor is found, especially when the donor cornea supply is small. In such instances, AMT can help the ophthalmologist buy some time by providing corneal surface restoration and stromal gain until a suitable graft material becomes available.

We made important observations on the corneal sensitivity changes with AMT. The pretransplantation corneal sensitivity was very low in all patients resulting from herpetic/infectious keratitis, diabetes, chemical burn, and previous surgeries, which might also have adverse effects on limbal stem cell population. We think that once corneal hypoesthesia sets in and persists, other sequela on the ocular surface can develop as a result of decreased corneal nerve trophism on epithelial functions, 
tear film deficiency, and exposure owing to interruption of corneal nerve mediated reflex arcs, that is, aqueous tear secretion and eye lid blinking. ${ }^{28}$ To our surprise, we saw that corneal sensitivity improved with AMT in nine eyes, which suggested that corneal nerve regeneration took place in our patients. Patients with herpetic keratitis and neurotrophic ulcers seemed to have benefited most in terms of corneal nerve recovery. It was interesting to see that none of the patients attained full corneal sensitivity at the final visit, which suggested that the recovery was limited and some disease process was still there. Even more interesting was our observation that ulcers remained healed despite the lack of full corneal sensitivity recovery. We would like to hypothesise that there may be a threshold corneal sensitivity level, which can provide sufficient trophic effects for the maintenance of epithelial milieu and functions, and that above this level corneal epithelium does not break down. It is also possible that corneal epithelium may be in jeopardy under the influence of certain disease states and that it may start to disintegrate once this threshold value is neared or reached. Yet, this assumption of ours has to be tested through further clinical and experimental studies. We used only preserved human amniotic membrane in this study. An alternative to this might be procurement and provision of fresh membranes when required. However, the theoretical possibility of disease transmission and the difficulties in finding a suitable fresh membrane donor sufficiently far in advance of surgery to allow processing and testing, and coordination with admission to hospital of the recipient should be remembered. Whether the use of preserved or fresh amniotic membranes or different storage times will have different effects on corneal epithelial, stromal, and nerve healing remains to be answered through controlled and larger studies. The changes and the differences in the levels of presumed trophic factors between fresh and preserved membranes and the effect of such variations on corneal wound healing awaits further studies. It was our belief that reduced corneal sensitivity together with the effects of the initial chemical, infectious, or the surgical insult would have an adverse outcome on the tear function parameters and ocular surface cytology. Indeed, five eyes had aqueous-deficient eyes and all eyes had BUT-deficient dry eyes. Schirmer test results did not change with AMT. BUT reduction most probably resulted from ocular surface irregularity and disturbed epithelial and goblet cell production of mucin quality and/or quantity. We observed limited BUT improvement with AMT owing to the attainment of epithelialisation and possible improvement of corneal and conjunctival epithelial mucin-related functions. We cannot answer clearly whether the tear film instability resulted from mucin deficiency in all patients since we did not quantify the mucin content of tears this time. To be able to provide more answers, we proceeded with conjunctival impression cytologic analysis, which provided evidence of squamous metaplasia, decreased goblet cell density, and slight to no mucin pick-up in all eyes before AMT. These parameters seemed to improve with AMT, which point to an increase in the ocular surface health, except for patient 10 in whom the amniotic membrane had to be removed. The extent of improvement seemed to be better in patients with herpetic and neurotrophic ulcers than the patients with chemical, postinfectious, or graft ulcers, which can be explained by the severity of the additive effects of the initial insult on the ocular surface, other ocular problems, and previous surgeries. To our knowledge, the only impression cytology study related to AMT was performed by Prabhasawat and Tseng ${ }^{29}$ in six patients with conjunctival defects following removal of ocular surface tumours or corneal pannus caused by aniridia, toxic epidermal necrolysis, and chemical burns where the defects were reconstructed by preserved human amniotic membrane transplantation. That study showed increased goblet cell density with AMT but lack of corneal epithelial phenotype even on avascular corneas, supporting the concept that conjunctival transdifferentiation does not occur in vivo and that limbal stem cell transplantation is needed for effective corneal surface reconstruction in patients with total limbal deficiency. ${ }^{29}$ However, patients with severe corneal ulcers and limbal deficiency who underwent limbal transplantation may still present challenges to the clinician after AMT as in case 8 because of associated lid problems and dry eye states. We did not encounter serious problems after AMT. Yet, we had to remove the amniotic membrane in case 10 upon discovery of profuse secretion where the cultures of the amniotic membrane and the bandage contact lens tested positive for Staphylococcus aereus infection. The amniotic membrane was prepared under sterile conditions and preserved in clean conditions, and the amniotic membranes cultured at operation were negative for microorganisms. We suspect the therapeutic contact lens as the source of infection in this patient, who frequently lost her lenses-one of the common problems after AMT in our patients. We would like to take this opportunity to remind the readership of this article that it is very important to debride the bottom of the ulcer and the poorly adherant epithelium at the edges to prevent postoperative infection and to aid healing. We would also like to draw attention to an important observation of ours in case 7 that stromal thinning may continue after AMT. Thus, a careful examination for progressive keratolysis after AMT is also essential before it is too late to take further measures.

In summary, we found that AMT can be helpful for the treatment of epithelial defects and stromal ulcers. 
We came to learn that cases with total limbal deficiency or extensive ocular surface inflammation may not be cured with AMT alone. AMT provides improvement of corneal sensitivity, tear film stability and impression cytology parameters. However, the entire mechanism of the healing effect of amniotic membrane is still unknown. A recent experimental study revealed that amniotic membrane transplantation vs tarsorraphy in murine HSV-1 stromal keratitis resulted in improvements in substance-P-related corneal nerve fibres in eyes treated with amniotic membrane, but not in eyes treated with tarsorraphy. ${ }^{30}$ We think that prospective, controlled, comparative studies of corneal ulcers treated by, for instance, tarsorraphy or other modalities should be performed to investigate whether the beneficial changes of amniotic membrane transplantation are greater or lesser than the changes that might have been observed by an alternative treatment. In this study, we tried to point to the effects of amniotic membrane transplantation on the ocular surface together with the problematic and unresolved issues. Thus, it is our sincere belief that further studies should be carried out along these lines.

\section{References}

1 Tsai RJF, Tseng SCG. Effect of stromal inflammation on the outcome of limbal transplantation for corneal surface reconstruction. Cornea 1995; 14: 439-449.

2 Foster CS, Zelt RP, Mai-Phan T, Kenyon KR. Immunosuppression and selective inflammatory cell depletion. Arch Ophthalmol 1982; 100: 1820-1824.

3 Aquavella JA. Therapeutic contact lenses. In: Aquavella JA, Rao GN (eds). Contact Lenses. Lippincott: Philadelphia, 1987, pp 140-163.

4 Pakarinen M, Tervo T, Tarkkanen A. Tarsorraphy in the treatment of persistent corneal lesions. Acta Ophthalmol Scand 1987; 182(Suppl): 69-73.

5 Dohlman $\mathrm{CH}$, Boruchoff SA, Sullivan GL. A technique for the repair of perforated corneal ulcers. Arch Ophthalmol 1967; 73: 471.

6 Lee SH, Tseng SCG. Amniotic membrane transplantation for persistent epithelial defects with ulceration. Am J Ophthalmol 1997; 123: 303-312.

7 Tsubota K, Satake Y, Ohyama M. Surgical reconstruction of the ocular surface in advanced cicatricial pemphigoid and Stevens Johnson Syndrome. Am J Ophthalmol 1996; 122: $38-52$.

8 Prabhasawat P, Barton K, Burkett G, Tseng SCG. Comparison of conjunctival autografts and primary closure for pterygium excision. Ophthalmology 1997; 104: 974-985.

9 Shimazaki J, Yang HY, Tsubota K. Amniotic membrane transplantation for ocular surface reconstruction in patients with chemical and thermal burns. Ophthalmology 1977; 104: 2068-2076.

10 Nelson JD. Impression cytology. Cornea 1988; 7: 71-81.

11 Dua HS, Azuara-Blanco A. Amniotic membrane transplantation. Br J Ophthalmol 1999; 83: 748-752.

$12 \mathrm{Na} \mathrm{BK}$, Hwang JH, Kim JC. Analysis of human amniotic membrane components as proteinase inhibitors for development of therapeutic agent for recalcitrant keratitis. In: Masaomi T, Toshio H, Ichiro T (eds). Trophoblast Research. New York: University of Rochester Press, 1999, pp 453-466.

13 Riley SC, Leask R, Denison FC. Secretion of tissue inhibitors of matrix metalloproteinase by human fetal membrane, decidua and placenta at parturition. J Endocrinol 1999; 162: 351-359.

14 Shinozaki M, Shoda A, Shimazaki J. Detection of basic fibroblast growth factor from amniotic membrane. Invest Ophthalmol Vis Sci 1995; 36: 131-138.

15 Lwebuga-Mukasa JS, Thulin G, Madri JA. An acellular human amniotic membrane model for in vitro culture of type II pneumocytes, the role of basement membrane in cell morphology and function. J Cell Physiol 1984; 121: 215-225.

16 Modesti A, Scarpa S, D'Orazi G. Location of type IV and V collagens in the stroma of human amnion. Prog Clin Biol Res 1989; 296: 459-463.

17 Behzad F, Jones CJ, Aplin JD. The role of integrin alpha 6 and 4 in hemidesmosomes of human amnion. Biochem Soc Trans 1991; 19: 389S.

18 Kurpakus MA, Stock EI, Jones JCR. The role of basement membrane in differential expression of keratin proteins in epithelial cells. Dev Biol 1992; 150: 243-255.

$19 \mathrm{Ni}$ J, Abrahamson M, Zhang M. Cystatin E is a novel human cysteine proteinase inhibitor with structural resemblance to family 2 cystatins. J Biol Chem 1997; 272: 10853-10858.

20 Cheong TB, Ko YS, Kwon NS. Heat shock protein can inhibit corneal fibroblast death from oxidative stress. Invest Ophthalmol Vis Sci 1999; 40: S3291.

21 Kruse FE, Rohrschneider K, Völcker HE. Multiple layer amniotic membrane transplantation for reconstruction of deep corneal ulcers. Ophthalmology 1999; 108: 1504-1511.

22 Hanada K, Shimazaki J, Shimmura S, Tsubota K. Multilayered amniotic membrane transplantation for severe ulceration of the cornea and sclera. Am J Ophthalmol 2001; 131: 324-331.

23 Letko E, Stechschulte SU, Kenyon KR, Sadeq N, Romero TR, Samson CM. Amniotic membrane inlay and overlay grafting for corneal epithelial defects and stromal ulcers. Arch Ophthalmol 2001; 119: 659-663.

24 Kim JS, Kim JC, Hahn TW, Park WC. Amniotic membrane transplantation in infectious corneal ulcer. Cornea 2001; 20: 720-726.

25 Chen HJ, Pires RTF, Tseng SCG. Amniotic membrane transplantation for severe neurotrophic ulcers. $\mathrm{Br} \mathrm{J}$ Ophthalmol 2000; 84: 826-833.

26 Gabric N, Mravicic I, Dekaris I, Karaman Z, Mitrovic S. Human amniotic membrane in the reconstruction of the ocular surface. Doc Ophthalmol 1999; 98: 273-283.

27 Anderson DF, Ellies P, Pires RTF, Tseng SCG. Amniotic membrane transplantation for partial limbal stem cell deficiency. Br J Ophthalmol 2001; 85: 567-575.

28 Tseng SCG, Tsubota K. Important concepts for treating ocular surface and tear disorders. Am J Ophthalmol 1997; 124: 825-835.

29 Prabhasawat P, Tseng SCG. Impression cytology study of epithelial phenotype of ocular surface reconstructed by preserved human amniotic membrane. Arch Ophthalmol 1997; 115: 1360-1367.

30 Heilingenhaus A, Bauer D, Meller D, Steuhl KP, Tseng SCG. Improvement of HSV-1 necrotizing keratitis with amniotic membrane transplantation. Invest Ophthalmol Vis Sci 2001; 42: 1969-1974. 